\title{
Determinación de $E$. coli biotipo 1 y $E$. coli 0157:H7 en canal de carne bovina en plantas de beneficio del departamento del Atlántico (Colombia)
}

\author{
$E$. coli biotype 1 and $E$. coli $0157: H 7$ determination in cattle carcasses at \\ processing plants in the department of Atlántico (Colombia) \\ David Rosado-Porto ${ }^{1}$, Jenifer Bonivento-Calvo ${ }^{1}$, Soraya Salcedo-Mendoza ${ }^{2}$, \\ Ailen Molina-Castillo², Ronald Maestre-Serrano ${ }^{3}$, Aracely García-Cuan ${ }^{3,4}$
}

\section{Resumen}

La contaminación de la canal con E. coli $\mathrm{O} 157: \mathrm{H} 7$, agente etiológico de la Enfermedad Diarreica Aguda (EDA), durante el sacrificio es la ruta primaria para la contaminación de la carne picada de vacuno. El objetivo del presente estudio fue determinar la prevalencia de $E$. coli biotipo 1 genérico y $E$. coli $\mathrm{O} 157: \mathrm{H} 7$ en bovinos sacrificados en plantas de beneficio del departamento del Atlántico. Se analizaron 224 canales de bovino provenientes de plantas de beneficio de cuatro municipios. Las muestras fueron procesadas en el Laboratorio de Salud Pública del departamento del Atlántico. Se determinó E. coli O157:H7 por el método VIDAS UP E. coli O157 (incluyendo H7) (ECPT) y E. coli biotipo 1, usando agar TBX (Oxoid), método ISO 16649-2:2000. La prevalencia de E. coli O157:H7 fue de $0.45 \%$ y de $E$. coli biotipo 1 genérico fue de $0.89 \%$ en muestras con recuentos de E. coli biotipo $1>100 \mathrm{UFC} / \mathrm{cm}^{2}$. En $54 \%$ de las canales con presencia de $E$. coli, las concentraciones oscilaron entre 1 y $758 \mathrm{UFC} / \mathrm{cm}^{2}$. Se concluye que la prevalencia de $E$. coli $\mathrm{O} 157: \mathrm{H} 7$ encontrada fue baja (0.45\%); sin embargo, indica presencia de esta cepa patógena en la zona, por lo que se requiere fortalecer la vigilancia para expendios y distribuidores.

Palabras clave: prevalencia, Escherichia coli genérica, E. coli $\mathrm{O} 157: \mathrm{H} 7$

\footnotetext{
${ }^{1}$ Programa de Microbiología, Universidad Libre seccional Barranquilla, Colombia

${ }^{2}$ Laboratorio de Salud Pública, Secretaria de Salud del departamento del Atlántico, Barranquilla, Colombia

${ }^{3}$ Facultad de Ciencias de la Salud, Universidad Libre seccional Barranquilla, Colombia

${ }^{4}$ E-mail: aracely.garciac@unilibre.edu.co; https://orcid.org/0000-0003-0047-4073
}

Recibido: 18 de agosto de 2020

Aceptado para publicación: 16 de febrero de 2021

Publicado: 23 de junio de 2021

CLos autores. Este artículo es publicado por la Rev Inv Vet Perú de la Facultad de Medicina Veterinaria, Universidad Nacional Mayor de San Marcos. Este es un artículo de acceso abierto, distribuido bajo los términos de la licencia Creative Commons Atribución 4.0 Internacional (CC BY 4.0) [https:// creativecommons.org/licenses/by/4.0/deed.es] que permite el uso, distribución y reproducción en cualquier medio, siempre que la obra original sea debidamente citada de su fuente original 


\begin{abstract}
Carcass contamination with E. coli $\mathrm{O} 157: \mathrm{H} 7$, the etiological agent of Acute Diarrheal Disease (ADD) during slaughter is the primary route for contamination of minced beef. The aim of this study was to determine the prevalence of generic $E$. coli biotype 1 and $E$. coli $\mathrm{O} 157: \mathrm{H} 7$ in cattle slaughtered in processing plants in the department of Atlántico. In total, 224 bovine carcasses from processing plants in four municipalities were analyzed. The samples were processed in the Public Health Laboratory of the department of Atlántico. E. coli $\mathrm{O} 157: \mathrm{H} 7$ were determined by the VIDAS UP method, E. coli $\mathrm{O} 157$ (including H7) (ECPT) and biotype 1 E. coli using TBX agar (Oxoid), ISO 16649-2: 2000 method. The prevalence of $E$. coli $\mathrm{O} 157: \mathrm{H} 7$ was $0.45 \%$ and of generic $E$. coli biotype 1 was $0.89 \%$ in samples with $E$. coli biotype 1 counts $>100 \mathrm{CFU} / \mathrm{cm}^{2}$. In $54 \%$ of the carcasses with the presence of $E$. coli, the concentrations ranged between 1 and $758 \mathrm{CFU} / \mathrm{cm}^{2}$. It is concluded that the prevalence of $E$. coli $\mathrm{O} 157: \mathrm{H} 7$ found was low $(0.45 \%)$; however, it indicates the presence of this pathogenic strain in the area, therefore, it is necessary to strengthen the surveillance for outlets and distributors.
\end{abstract}

Key words: prevalence, generic Escherichia coli, E. coli $\mathrm{O} 157: \mathrm{H} 7$

\section{INTRODUCCIÓN}

Colombia se ubica entre los primeros 11 productores de carne a nivel mundial; sin embargo, las exportaciones de este producto son bajas (<1\%) (MADR - MCIT, 2010), debido a la falta de calidad de carne competitiva que requieren los mercados mundiales. Según el CONPES 3376 de la política sanitaria y de inocuidad de las cadenas de carne bovina y leche, solo el 1\% de las 1311 plantas de beneficio que aproximadamente existen en el país, cumplen con los requisitos sanitarios y ambientales (CONPES, 2005).

Escherichia coli es un bacilo gramnegativo de la familia Enterobacteraceae. Bacteria anaeróbica facultativa, quimiorganotrófica, capaz de crecer con metabolismo respiratorio y fermentativo. E. coli tiene una función útil en el cuerpo inhibiendo el crecimiento de especies de bacterias patógenas y sintetizando cantidades apreciables de vitaminas (Stecher y Hardt, 2008; Bélanger et al., 2011). E. coli biotipo 1 no patógena, lla- mada también $E$. coli genérica, es indicador de contaminación de los alimentos con materia fecal por bacterias perjudiciales o patógenas para el hombre que tienen como hábitat común el intestino (Michanie, 2003).

E. coli se clasifica en seis grupos: $E$. coli enteropatógena (EPEC), STEC, E. coli enterotoxigénica (ETEC), E. coli enterohemorrágica (EHEC), E. coli enteroagregativa (EAEC), E. coli enteroinvasiva (EIEC), y un nuevo patotipo $E$ coli invasiva adherente (AIEC) (Croxen et al., 2013). E. coli enterohemorrágica es un subconjunto de cepas patógenas STEC (OMS, 2015; Heredia y García, 2018). E. coli O157:H7, del grupo filogénico E, es una cepa enterohemorrágica (EHEC) que produce grandes cantidades de una o más toxinas relacionadas, que causan daño severo en el revestimiento del intestino (Feng y Reddy, 2013; OMS, 2018); toxinas que están estrechamente relacionadas con las toxinas producidas por Shigella dysenteriae. La enfermedad aguda causada por la bacteria es llamada colitis hemorrágica y es caracterizada por severos 
cólicos y diarrea (OMS, 2018). Adicionalmente, la infección por E. coli $\mathrm{O} 157: \mathrm{H} 7$ puede causar el síndrome urémico hemolítico (SUH), enfermedad severa caracterizada por hemolisis y fallos renales (Raina et al., 2019). Su nombre se origina del antígeno somático [O] 157 identificado y el séptimo antígeno flagelar $[\mathrm{H}]$. El antígeno [O] se deriva de la pared celular y el $[\mathrm{H}]$ del flagelo que se encuentra solo en especies motiles (Bryan et al., 2015).

El ganado es uno de los principales reservorios de E. coli O157:H7. La contaminación de la canal durante el sacrificio es la ruta primaria que últimamente conduce a la contaminación de la carne picada de vacuno (Varela-Hernández et al., 2007; FSIS, 2015; Jure et al., 2015; ACHIPIA, 2018). Sin embargo, también se ha identificado a otros alimentos como la lechuga, coles de bruselas, hortalizas, leche cruda y el agua como vehículos de su transmisión (Rubeglio y Tesone, 2007; Puig-Peña et al., 2013; CDC, 2018). Asimismo, el contacto directo con animales portadores del microorganismo se ha reconocido como una fuente de infección (FAO, 2011; Franco-Anaya et al., 2013).

Por otro lado, la alta demanda de productos animales para el consumo como fuente principal de proteínas en la dieta, debido al crecimiento de la población humana y la globalización, han conllevado a un mayor movimiento de alimentos a nivel mundial (OMS, 2015), que junto a malas prácticas en el procesamiento, aumentan el riesgo de contaminación por patógenos transmitidos por alimentos en cualquier punto desde la granja hasta la cadena de tenedores (Wilson et al., 1996; FAO, 2007; Dhama et al., 2013; Heredia y García, 2018).

Este microorganismo fue identificado en Colombia en 1996; sin embargo, son pocos los trabajos realizados acerca de la frecuencia de esta bacteria en productos alimenticios. En la sabana de Bogotá, se registró $E$. coli $\mathrm{O} 157$ en 1/300 muestras de productos cárnicos y lácteos artesanales (Franco et al., 2001) y en Córdoba se identificó E. coli O157:H7 en el 2\% de canales bovinas y 10\% en carne molida (Piedrahita et al., 2001), de allí la importancia que este microorganismo se contemple dentro de análisis de riesgos y puntos críticos de control de las plantas de beneficio, al ser un agente etiológico de brotes de Enfermedad Diarreica Aguda (EDA) en la región (Mattar et al., 2001; Medina et al., 2010; Rúgeles et al., 2010; GómezDuarte, 2014). Se desconoce la prevalencia de E. coli O157: H7 en carne bovina en el departamento del Atlántico, a pesar de contar con las plantas de beneficio más grandes del país (Bonivento-Calvo et al., 2011). Ante esto, el objetivo del presente trabajo consistió en determinar la prevalencia de $E$. coli biotipo I y E. coli $\mathrm{O} 157: \mathrm{H} 7$ en los bovinos sacrificados en plantas de beneficio del departamento del Atlántico (Colombia).

\section{Materiales y Métodos}

\section{Población de Estudio y Muestreo}

La población de estudio estuvo conformada por canales de bovinos de las plantas de beneficio ubicadas en los municipios de Soledad, Malambo, Galapa y Sabanalarga en el departamento del Atlántico, Colombia durante los meses de marzo a septiembre de 2013. En la Región Caribe, el periodo de las precipitaciones anuales se presenta entre mayo a octubre y el periodo seco entre de diciembre a abril. Estas empresas se encuentran registradas ante el Instituto Nacional de Vigilancia de Medicamentos y Alimentos (INVIMA).

Para la selección de las plantas de beneficio se realizó un muestreo aleatorio simple y se calculó el tamaño de la muestra a través del software Epi Info 3.2.2, basándose en una prevalencia de E. coli $\mathrm{O} 157: \mathrm{H} 7$ del $2 \%$, con un nivel de confianza de $95 \%$ y un error permitido de 5\%. El tamaño de la muestra calculado fue de 224 canales de bovi- 
no; los cuales, se distribuyeron de forma proporcional de acuerdo con el porcentaje que aporta cada planta de beneficio al total de producción día.

Las muestras de canales de bovino se tomaron empleando el método de la esponja (Malandrini et al., 2001; Rodríguez-Cordero y Carrascal-Camacho, 2016). Durante el proceso de toma de muestras se recolectó información epidemiológica de los bovinos analizados tales como: sexo, edad, procedencia del animal y número de guía de transporte. Las muestras se mantuvieron en cadena de frío a $4{ }^{\circ} \mathrm{C}$ y se transportaron al Laboratorio de Salud Pública del departamento del Atlántico para su procesamiento.

\section{E. coli Biotipo 1 y E. coli O157:H7}

La determinación de E. coli $\mathrm{O} 157: \mathrm{H} 7$ se realizó empleando el método de VIDAS UP E. coli O157 (incluyendo H7) (ECPT) que se basa en la metodología ELFA (Enzyme Linked Fluorescent Assay). El análisis se realizó teniendo en cuenta los procedimientos establecidos para leche cruda, quesos de leche cruda y muestras ambientales de entornos de producción. Los resultados positivos fueron aislados en Agar McConkey sorbitol (SMAC) (bioMérieux) con cefixima y telurito e incubados a $37 \pm 1{ }^{\circ} \mathrm{C}$, durante 18 24 horas y Agar ChromoID O157:H7 (bioMérieux), sin la mezcla de cefixima y telurito e incubados a $37^{\circ} \mathrm{C}$ durante $18-24$ horas. Los resultados de colonias sorbitol negativas positivas para $E$. coli $\mathrm{O} 157: \mathrm{H} 7$ fueron confirmadas utilizando el kit E. coli $\mathrm{O} 157$ Látex Test (Oxoid, Alemania) para la aglutinación con suero anti-O157.

La determinación de E. coli biotipo 1 se realizó en agar TBX pH 7.2 (Tryptone Bile Glucuronic Agar, por sus siglas en inglés, Oxoid) por el método ISO 16649-2:2000: Microbiology of food and animal feeding stuffs-horizontal method for the enumeration of $\beta$-glucuronidase positive E. coli.

\section{Cepas de Referencia y Metodología}

Como cepas de referencias se incluyeron las cepas de E. coli ATCC 25922 y un aislado de E. coli $\mathrm{O} 157: \mathrm{H} 7$ donado por el Instituto Nacional de Vigilancia de Medicamentos y Alimentos (INVIMA) y utilizados en los procesos de verificación y aseguramiento de calidad. Asimismo, se incluyó la cepa Staphylococcus aureus ATCC 29213 como control negativo en los procesos de aseguramiento de calidad de determinación de $E$. coli biotipo 1 .

Se realizaron pruebas de estandarización del inóculo de $E$. coli $\mathrm{O} 157: \mathrm{H} 7$, con concentraciones bacterianas teóricas de 1000, 100, 10 y $1 \mathrm{UFC} / \mathrm{ml}$, con un tiempo de incubación de 24 horas. En la verificación de la metodología VIDAS se realizó la adición de E. coli O157:H7 a muestras de superficie de carne de canal adicionada con vancomicina, con el objeto de verificar la capacidad de recuperación del microorganismo en la matriz de trabajo. Se trabajaron las diluciones: $10^{-10}, 10^{-9}$, $10^{-8}$ y la concentración de UFC fue confirmada por recuento en placa con Agar Plate Count (Merck) realizado por duplicado.

Los medios de cultivos utilizados durante el desarrollo del estudio fueron valorados de acuerdo con lo descrito por la norma ISO 11133-2/2011.

\section{Análisis de Datos}

Los datos de estandarización del inóculo fueron transformados a logaritmo base $10 \mathrm{y}$ se realizó un análisis de regresión, estimándose el coeficiente de correlación de la curva. Para los análisis de prevalencia de E. coli O157:H7 y E. coli biotipo 1 se realizó un análisis univariado de las variables cuantitativas, con una estadística descriptiva de acuerdo con el tipo de variable analizada. Los datos fueron analizados a través de Microsoft Excel 2013 y SPSS v. 23. Los resultados obtenidos fueron comparados con los valores máximos permisibles descritos en la Resolución 2905 
Cuadro 1. Estandarización de inóculo de E. coli $\mathrm{O} 157: \mathrm{H} 7$

\begin{tabular}{|c|c|c|}
\hline Dilución & $\begin{array}{l}\text { Promedio } \\
\text { (UFC*ml) }\end{array}$ & $\begin{array}{l}\text { CV } \\
(\%)\end{array}$ \\
\hline $10^{-6}$ & $1072.9 \pm 104.2$ & 9.7 \\
\hline $10^{-7}$ & $133.5 \pm 13.2$ & 9.9 \\
\hline $10^{-8}$ & $15.5 \pm 6.3$ & 40.7 \\
\hline $10^{-9}$ & $3.2 \pm 3.3$ & 103.0 \\
\hline $10^{-10}$ & $0.93 \pm 0.9$ & 98.7 \\
\hline
\end{tabular}

Cuadro 2. Verificación de método VIDAS para la determinación de $E$. coli $\mathrm{O} 157: \mathrm{H} 7$

\begin{tabular}{ccc}
\hline Muestra & $\begin{array}{c}\text { Cantidad } \\
\text { adicionada } \\
\text { (UFC) }\end{array}$ & $\begin{array}{c}\text { Resultado } \\
\text { VIDAS }\end{array}$ \\
\hline 1 & $32 \pm 8.5$ & + \\
2 & $16.0 \pm 4.2$ & + \\
3 & $14.0 \pm 2.8$ & + \\
4 & $7.0 \pm 1.4$ & + \\
5 & 2.0 & + \\
6 & $1.5 \pm 0.7$ & + \\
7 & $0.5 \pm 0.7$ & - \\
8 & 0 & - \\
9 & 0 & - \\
\hline
\end{tabular}

Error expresado en desviación estándar

de 2007, ratificada por la Resolución 2690 de 2015 del Ministerio de Protección Social y Ministerio de Agricultura y Desarrollo Social (Ministerio de Agricultura y Desarrollo Rural y Ministerio de Salud y Protección social, 2015).

\section{Resultados}

\section{Estandarización de Inóculo y Verificación de Método VIDAS}

Los resultados de estandarización del inóculo de $E$. coli $\mathrm{O} 157: \mathrm{H} 7$ mostraron un buen ajuste de los recuentos obtenidos con un coeficiente de correlación de 0.976 de la curva de calibración del microorganismo y con medidas de dispersión que permitieron realizar fortificaciones de las muestras de frotis de canales de reses con un nivel de precisión suficiente para verificar el método VIDAS UP E. coli O157 (incluyendo H7) (Cuadro 1 y Figura 1).

En cuanto a la verificación del método VIDAS UP E. coli O157 (incluyendo H7), los resultados demostraron un límite de detección de $1.5 \pm 0.7 \mathrm{UFC} / \mathrm{cm}^{2}$ de E. coli O157:H7. No se observaron falsos positivos ante la inoculación de otra cepa de $E$. coli en las muestras (Cuadro 2).

\section{Prevalencia de $E$. coli $0157: H 7$ y $E$. coli} Biotipo 1

Se encontró una prevalencia de $E$. coli O157:H7 de 0.45\%. Asimismo, las muestras que no se encontraron conforme a lo establecido en la Resolución 2905 de 2007, ratificada por la resolución 2690 de 2015, presentaron recuentos de $E$. coli biotipo 1 genérico mayores a $100 \mathrm{UFC} / \mathrm{cm}^{2}$ y prevalencia de $0.89 \%$ (Cuadro 3 ); sin embargo, las concentraciones de $E$. coli biotipo 1 oscilaron entre $1 \mathrm{UFC} / \mathrm{cm}^{2}$ y $758 \mathrm{UFC} / \mathrm{cm}^{2}$ en las muestras analizadas, y con presencia de E. coli en $54 \%$ de las canales. El recuento se basó en la norma NTC 1325 quinta actualización que indica como referencia $<100 \mathrm{UFC} / \mathrm{cm}^{2}(39,40)$ (NTC 1325, 2008).

En cuanto a la muestra positiva para $E$. coli $\mathrm{O} 157: \mathrm{H7}$, la canal bovina correspondió a una hembra de 3 años proveniente del departamento de Sucre (Cuadro 4). Las muestras de E. coli biotipo 1 con recuentos su- 


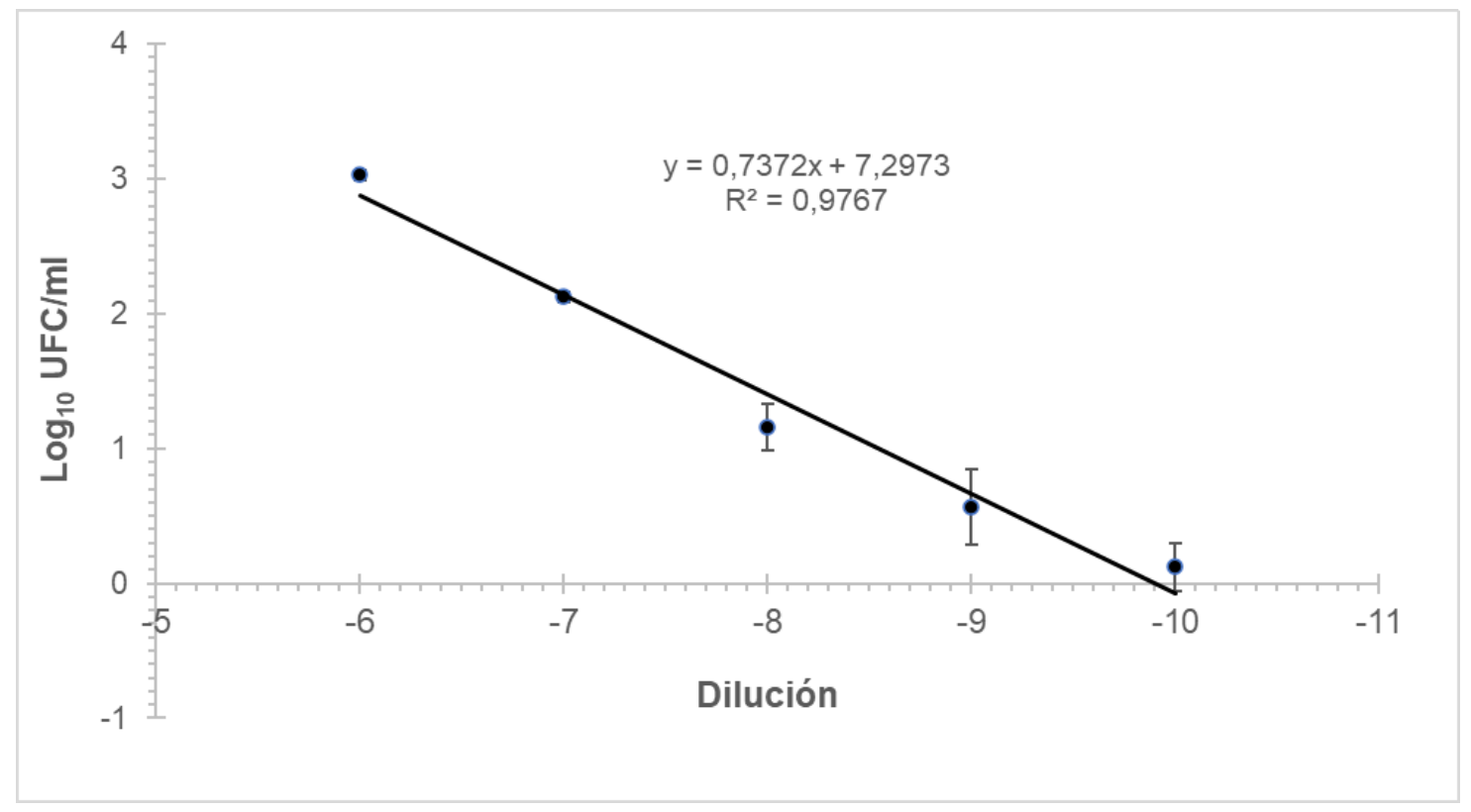

Figura 1. Regresión lineal de estandarización de inóculo de E. coli $\mathrm{O} 157: \mathrm{H} 7$

periores a $100 \mathrm{UFC} / \mathrm{cm}^{2}$ correspondieron a un macho de 3 años y una hembra de 6 años, provenientes de los departamentos de Cesar y Atlántico, respectivamente. Un alto porcentaje de las reses que fueron procesadas provenían de los departamentos de Magdalena, Atlántico y Cesar (46.4, 17.8 y 15.2\%, respectivamente). Además, un gran porcentaje de las reses sacrificadas $(78.1 \%)$ correspondían a machos, de estos, $(68.3 \%)$ de 3 años de edad, provenientes de los departamentos de Magdalena, Cesar y Atlántico.

\section{Discusión}

En este estudio se evidenció que 54\% de las canales de bovino de 224 canales analizadas se encontró la presencia de $E$. coli biotipo 1 genérica a partir de técnicas microbiológicas tradicionales. La presencia de este microorganismo en un alimento indica una contaminación directa o indirecta de origen fecal; no obstante, no constituye un indicio directo de la presencia de un patóge- no, sino que implica solamente un cierto riesgo de que pudiera estar presente (Stevens et al., 2003).

La determinación de E. coli $\mathrm{O} 157$ se realizó mediante la metodología VIDAS ${ }^{\circledR} \mathrm{UP}$ E. coli $\mathrm{O} 157$ (incluyendo H7), Vitek Inmuno Diagnostic Assay System (bioMérieux), que es un método establecido como rápido y de rutina por su facilidad de ensayo, emplea anticuerpos monoclonales o policlonales para detectar microorganismos patógenos y ha sido adoptado por la Association of Oficial Analytical Chemists (AOAC). Los resultados fueron confirmados a su vez por medio del kit E. coli O157 Látex Test (Oxoid) para la aglutinación con suero anti-0157. El método VIDAS UP es mucho más rápido y efectivo que los métodos tradicionales para detectar E. coli O157 (Fung, 2002; Law et al., 2015).

El uso de esta metodología para la detección de E. coli $\mathrm{O} 157$ ha sido reportado en diversas matrices; por ejemplo, en muestras de quesos de leche cruda (Carvalho-Nunes 
Cuadro 3. Prevalencia de E. coli $\mathrm{O} 157: \mathrm{H} 7$ y E. coli biotipo 1 en canales bovinas en plantas de beneficio del departamento del Atlántico, Colombia

\begin{tabular}{lcc}
\hline Microorganismo & $\begin{array}{c}\text { Negativo } \\
\mathrm{n}(\%)\end{array}$ & $\begin{array}{c}\text { Positivo } \\
\mathrm{n}(\%)\end{array}$ \\
\hline E. coli O157:H7 & $223(99.55)$ & $1(0.45)$ \\
E. coli biotipo 1 & $222(99.11)$ & $2(0.89)$ \\
\hline
\end{tabular}

$\mathrm{n}$ : Frecuencia absoluta; \%: Frecuencia relativa

Cuadro 4. Prevalencia de E. coli biotipo 1 y E. coli $\mathrm{O} 157: \mathrm{H} 7$ en canales bovinas en plantas de beneficio del departamento del Atlántico, Colombia por sexo y departamento de procedencia (Colombia)

\begin{tabular}{|c|c|c|c|c|c|c|c|c|c|c|}
\hline \multirow{3}{*}{ Procedencia } & \multirow{3}{*}{$\mathrm{H}$} & \multirow{3}{*}{ M } & \multicolumn{4}{|c|}{ Hembra } & \multicolumn{4}{|c|}{ Macho } \\
\hline & & & \multicolumn{2}{|c|}{$\begin{array}{c}\text { E. coli } \\
\text { biotipo } 1\end{array}$} & \multicolumn{2}{|c|}{$\begin{array}{c}\text { E. coli } \\
\text { O157:H7 }\end{array}$} & \multicolumn{2}{|c|}{$\begin{array}{c}\text { E. coli } \\
\text { biotipo } 1\end{array}$} & \multicolumn{2}{|c|}{$\begin{array}{c}\text { E. coli } \\
\text { O157:H7 }\end{array}$} \\
\hline & & & $-(\%)$ & $+(\%)$ & $-(\%)$ & $+(\%)$ & $-(\%)$ & $+(\%)$ & $-(\%)$ & $+(\%)$ \\
\hline Atlántico & 8 & 32 & 3.1 & 0.4 & 3.6 & 0 & 14.3 & 0 & 14.3 & 0 \\
\hline Bolívar & 3 & 11 & 1.3 & 0 & 1.3 & 0 & 4.9 & 0 & 4.9 & 0 \\
\hline Cesar & 0 & 34 & 0 & 0 & 0 & 0 & 14.7 & 0.4 & 15.2 & 0 \\
\hline Córdoba & 0 & 16 & 0 & 0 & 0 & 0 & 7.1 & 0 & 7.1 & 0 \\
\hline Magdalena & 31 & 73 & 13.8 & 0 & 13.8 & 0 & 32.6 & 0 & 32.6 & 0 \\
\hline $\begin{array}{l}\text { Norte de } \\
\text { Santander }\end{array}$ & 1 & 0 & 0.5 & 0 & 0.4 & 0 & 0 & 0 & 0 & 0 \\
\hline Sucre & 4 & 11 & 1.8 & 0 & 1.3 & 0.4 & 4.9 & 0 & 4.9 & 0 \\
\hline Total & 47 & 177 & & & & & & & & \\
\hline
\end{tabular}

H: hembra; M: macho; -: negativo; +: positivo

et al., 2014), en leche cruda y muestras de menudo de pollo (Reuben et al., 2003). Así mismo, Elizaquível-Bárcenas (2009) comparó tres kits comerciales para detección de $E$. coli $\mathrm{O} 157$, incluyendo el VIDAS UP, contra una metodología de qPCR (PCR en tiempo real) demostrando una mayor especificidad para la metodología VIDAS UP, donde detectó una cantidad inicial de 10 UFC en tanto que fue de 100 UFC para qPCR.
Al realizar la estandarización de inóculos y verificación de técnicas en este estudio se pudo demostrar que la técnica VIDAS UP es igualmente eficaz en cuanto a la especificidad a lo reportado por la literatura, ya que se comprobó que la técnica detecta desde 1 UFC. Las ventajas de la PCR se cuestionan para la detección de patógenos en alimentos, ya que se puede detectar células muertas y que su sensibilidad está limitada por el tama- 
ño de la muestra en el tubo de reacción. Estas limitaciones se han abordado introduciendo un paso de enriquecimiento previo a la detección por PCR, lo que permite el crecimiento de las células vivas y la recuperación de las células dañadas, aumentando su número y en consecuencia la sensibilidad en la detección (Elizaquível-Bárcenas, 2009).

La identificación de la presencia de $E$. coli $\mathrm{O} 157: \mathrm{H} 7$ en carne vacuna de consumo es un tema de gran impacto para la salud pública a nivel mundial. Entidades como la Organización de las Naciones Unidas para la Alimentación y la Agricultura (FAO) y la Organización Mundial de la Salud (OMS) reconocen al ganado bovino como el principal reservorio natural de esta cepa infecciosa de E. coli, y a la carne fresca y la leche cruda como los vehículos más comunes de infección para el humano, principalmente el consumo de carne molida mal cocida (OMS, 2015, 2018).

Las condiciones de la cadena de producción son diferentes de un país a otro, lo que se refleja en la prevalencia de $E$. coli O157 en carne de bovino. En una revisión realizada en reportes del Centro para el Control y Prevención de Enfermedades (CDC) en los Estados Unidos, se hallaron 350 reportes en 49 estados de brotes de la cepa de $E$. coli O157:H7 entre 1982 y 2002, en los cuales se confirmó a la carne molida contaminada como el vehículo de contagio en $41 \%$ de los casos (Rangel et al., 2005). Por otro lado, en Chile y Argentina se ha reportado ampliamente la presencia de esta cepa en carne vacuna para consumo, mayormente en carne molida, debido al mayor riesgo de infección durante las fases de procesamiento (Brusa et al., 2009; Masana et al., 2010; Jure et al., 2015; Cap et al., 2019). Asimismo, en un estudio realizado en México se identificó E. coli $\mathrm{O} 157: \mathrm{H} 7$ en el $2.6 \%$ de las muestras de canales bovinas (Reyes-Rodríguez et al., 2013), mientras que, en Lima, Perú, se aisló E coli. O157:H7 en $1.54 \%$ de 195 muestras de carne molida fresca obtenida de diferentes mercados de abastos de la ciudad (Méndez et al., 2013).
En Colombia no se ha determinado una prevalencia concreta de E. coli $\mathrm{O} 157: \mathrm{H} 7$ en carne bovina; sin embargo, Mattar y Vásquez (1998) indicaron una incidencia en bovino sanos de $6.5 \%$, comprobando que el ganado sano es efectivamente un reservorio de este agente de importancia para la salud pública. Dadas estas cifras, la investigación para determinar la presencia de E. coli $\mathrm{O} 157: \mathrm{H} 7 \mathrm{se}$ ha convertido en un área de investigación importante para los implicados en el sector de producción bovina; sin embargo, el estudio de Rúgeles et al. (2010) y el presente, si bien determinan una baja presencia de $E$. coli O157:H7, también son indicativos que estas cifras han disminuido notablemente con el paso de los años, posiblemente, por la implementación de políticas públicas que han impactado en los procesos de calidad al interior de las plantas de beneficio del país. No obstante, cabe indicar que $81 \%$ de las plantas de beneficio en Colombia son propiedad de los municipios y operan sin consultar la normatividad, ni los factores ambientales, sanitarios y de mercado que los haga viables; por tanto, no cumplen los requisitos ambientales, ni sanitarios y de ellos, $41 \%$ sacrifica en el piso (Acero et al., 2013).

\section{Conclusiones}

- La técnica VIDAS UP aporta una alternativa con alta sensibilidad y especificidad de acuerdo con lo reportado por la literatura y lo encontrado en este estudio. Además, presentó un desempeño óptimo en las matrices cárnicas evaluadas.

- Se encontró una baja prevalencia de $E$. coli $\mathrm{O} 157: \mathrm{H} 7$; sin embargo, ante la presencia de esta cepa patógena en el departamento del Atlántico, se debe fortalecer su vigilancia, extendiéndola a expendios y distribuidores.

- En el $54 \%$ de las canales de bovino se evidenció E. coli biotipo 1 generica. 


\section{Agradecimientos}

Expresamos agradecimientos al INVIMA por el suministro de cepas de referencias y a las plantas de beneficio que participaron en el estudio por toda la logística brindada. El presente proyecto de investigación fue financiado por la Secretaría de Salud del departamento del Atlántico y la Universidad Libre Seccional Barranquilla.

\section{Literatura Citada}

1. Acero R, Riaño G, Cardona D. 2013. Evaluación del sistema de gestión ambiental de los frigoríficos cárnicos en Colombia. Criterio libre 11:93-123.

2. [ACHIPIA] Agencia Chilena para la Calidad e Inocuidad Alimentaria. 2018. Escherichia coli productoras de toxinas Shiga 0157:H7 y No 0157 en carne bovina, Chile. [Internet]. Disponible en: https://www.achipia.gob.cl/wpcontent/uploads/2018/06/Perfil-de-Riesgo-E-coli-STEC-en-carne-bovina-v12018-1.pdf

3. Bélanger L, Garenaux A, Harel J, Boulianne M, Nadeau E, Dozois ChM. 2011. Escherichia coli from animal reservoirs as a potential source of human extraintestinal pathogenic $E$. coli. FEMS Inmunology Med Mic 62: 1-10. doi:10.1111/j.1574-695X.2011.00797.x

4. Bonivento-Calvo JC, Molina-Castillo AM, Maestre-Serrano $R$, GarcíaCuan A. 2011. E coli 0157:H7 en las canales de bovinos en las plantas de beneficio, un peligro biológico con gran impacto para la salud pública. Biociencias 6: 53-61.

5. Brusa V, Palacios M, Loup V, Copes $J$, Pineda G, Brocardo S, Aliverti $V$, et al. 2009. Evaluación de un sistema de PCR en tiempo real para la detección de Escherichia coli $\mathrm{O} 157: \mathrm{H} 7$ a partir de carne bovina molida. Analecta Vet 29: 5-8.
6. Bryan A, Youngster I, McAdam AJ. 2015. Shiga toxin producing Escherichia coli. Clin Lab Med 35: 247-272.

7. Carvalho-Nunes $R$, De Oliveira AN, De Mesquita AJ, Minafra e Rezende CS, Queiroz de Mesquita A, Mazzoni Romero RA. 2014. PCR and ELISA (VIDAS ECO 0157®) Escherichia coli 0157:H7 identification in Minas Frescal cheese commercialized in Goiâna, GO. Braz J Microbiol 45: 7-10.

8. Cap M, Carbonari CC, D'Astek BA, Zolezzi G, Deza N, Palladino MP, Masanaa M, Chinenb I, Rivas $M$. 2019. Frequency, characterization, and genotypic analysis of Shiga toxinproducing Escherichia coli in beef slaughterhouse of Argentina. Rev Argent Microbiol 51: 32-38.

9. [CDC] Centro para el Control y Prevención de Enfermedades. 2018. Brote multiestatal de infecciones por $E$. coli 0157:H7 vinculado a la lechuga romana (actualización final). [Internet]. Disponible en: https://www.cdc.gov/ecoli/ 2018/o157h7-04-18/index-esp.html

10. [CONPES] Consejo Nacional de Política Económica y Social, Republica de Colombia. 2005. Documento CONPES 3376: Política sanitaria y de inocuidad para las cadenas de la carne bovina y de la leche. [Internet]. Disponible en: https://www.minambiente.gov.co/images/normativa/conpes/2005/ Conpes_3376_2005.pdf

11. Croxen MA, Law RJ, Scholz R, Keeney KM, Wlodarska M, Finlay BB. 2013. Recent advances in understanding enteric pathogenic Escherichia coli. Clin Microbiol Rev 26: 822-880.

12. Dhama K, Rajagunalan S, Chakraborty S, Kumar A, Kumar A, Tiwari R, Kapoor S. 2013. Foodborne pathogens of animal origin - diagnosis, prevention, control and their zoonotic significance: a review. Pak J Biol Sci 16: 1076-1085. doi: 10.3923/pjbs.2013.1076.1085 
13. Elizaquível-Bárcenas P. 2009. Detección y cuantificación de Escherichia coli 0157:H7, Listeria monocytogenes, Salmonella spp y Stafilococcus aureus en alimentos vegetales mediante PCR en tiempo real. Tesis Doctoral. Valencia, España: Universitat de València. 212 p.

14. [FAO] Organización de las Naciones Unidas y la Alimentación para la Agricultura. 2007. Manual de buenas prácticas para la industria de la carne. Roma: FAO. [Internet]. Disponible en: http:// www.fao.org/3/y5454s/y5454s00.pdf

15. [FAO] Organización de las Naciones Unidas para la Alimentación y la Agricultura. 2011. Prevención de la $E$. coli en los Alimentos. [Internet]. Disponible en: http://www.fao.org/fileadmin/ user_upload/fcc/news/FAO_PREVENCION.de.la.E.Coli.en.los.ALIMENTOS_FCC_ES.pdf

16. Feng PC, Reddy S. 2013. Prevalences of Shiga toxin subtypes and selected other virulence factors among Shigatoxigenic Escherichia coli strains isolated from fresh produce. Appl Environ Microb 79: 6917-6923. doi: 10.1128/ AEM.02455-13

17. [FSIS] Servicio de Inocuidad e Inspección de los Alimentos. 2015. Validación de sistemas de Análisis de Peligros y de Puntos Críticos de Control (HACCP) según las pautas de cumplimiento del Servicio de Inocuidad e Inspección de los Alimentos. [Internet]. Disponible en: https://www.fsis.usda.gov/wps/wcm/connect/61 efecad1782-461d-a4bb-3a07fae 84826/ H A C C P - S ys tem s - Validation Spanish.pdf?MOD=AJPERES

18. Franco L, Vargas $X$, Mendoza $A$, Bayona M, Plaza A. 2001. Determinación de Escherichia coli 0157 a partir de productos cárnicos y lácteos artesanales empleando dos sistemas de aislamiento. Univ Sci 6: 23-30.

19. Franco-Anaya PA, Ramírez-Medina LM, Orozco-Ugarriza ME, LópezGutiérrez LA. 2013. Determinación de
Escherichia coli e identificación del serotipo 0157:H7 en carne de cerdo comercializada en los principales mercados de la ciudad de Cartagena. Rev Lasallista Investig 10: 91-100.

20. Fung D. 2002. Rapid methods and automation in microbiology. Compr Rev Food Sci. F 1: 3-22.

21. Gómez-Duarte OG 2014. Enfermedad diarreica aguda por Escherichia coli enteropatógenas en Colombia. Rev Chilena Infectol 31: 577-586.

22. Heredia N, García S. 2018. Animals as source of food-borne pathogens: a review. Anim Nutr 4: 250-255. doi: 10.1016/j.aninu.2018.04.006

23. [ISP, Chile] Instituto de Salud Pública Gobierno de Chile. 2017. Vigilancia de laboratorio de E. coli productora de toxina Shiga, Chile 2010-2016. Bol Vigilancia 7(6)

24. Jure MA, Condorí MS, PérezTerrazzino G, Catalán MG, LópezCampo A, Zolezzi G, Chinen I, Rivas M, Castillo M. 2015. Aislamiento y caracterización de Escherichia coli 0157 en productos bovinos y medias reses en la provincia de Tucumán. Rev Argent Microbiol 47: 125-131.

25. Law JW, Ab Mutalib NS, Chan KG, Lee LH. 2015. Rapid methods for the detection of foodborne bacterial pathogens: principles, applications, advantages, and limitations. Front Microbiol 5: 770.

26. [MADR] Ministerio de Agricultura y Desarrollo Rural, [MCIT] Ministerio de Comercio, Industria y Turismo. 2010. Planes de desarrollo para cuatro sectores claves de la agroindustria. Diagnóstico del sector en el mundo y punto de partida. Sector: Carne Bovina 2010. República de Colombia. [Internet]. Disponible en: http://www.andi.com.co/ Uploads/Plan-de-Negocios-CarneBovina.pdf

27. Malandrini J, Sirena J, Santa Cruz $R$, de la Vega Tapia M, Pizarro $C$. 2001. Toma de muestras de las superfi- 
cies de carcasas bovinas en el frigorífico municipal. Rev Cienc Téc 7: 225-232.

28. Masana MO, Leotta GA, Del Castillo L.L, D'Astek BA, Palladino PM, Galli L, Villacoba E, et al. 2010. Prevalence, characterization, and genotypic analysis of Escherichia coli 0157:H7 / NM from selected beef exporting abattoirs of Argentina. J Food Protect 73: 649-656. doi: 10.4315/0362-028x-73.4.649

29. Mattar S, Vásquez E. 1998. Escherichia coli $\mathrm{O} 157: \mathrm{H} 7$ infection in Colombia. Emerg Infect Dis 4: 126-127. doi: 10.3201/eid0401.980120

30. Mattar S, Visbal J, Arrieta G. 2001. E. coli 0157:H7 enterohemorrágico: un agente etiológico de diarrea y zoonosis en Colombia subestimado. Parte I. Rev MVZ Córdoba 6: 15-23.

31. Medina MG, Esquivel P, Lifschitz V, Medina ML, Lösch LS, Merino LA. 2010. Detección de Escherichia coli diarreogénicos en niños de barrios humildes de Corriente, Argentina. Rev Cubana Med Trop 62: 15-23.

32. Méndez CR, Vergara $G$ Morante HY, Flores PR, Gamboa RA. 2013. Aislamiento y caracterización de Escherichia coli 0157:H7 a partir de carne molida de bovino en Lima-Perú. Rev Perú Biol 20: 159-164.

33. Michanie S. 2003. Escherichia coli 0157:H7, la bacteria que disparar el HACCP en la industria de la carne. Rev Ganado y Carne 3: 40-42.

34. Ministerio de Agricultura y Desarrollo Social, Ministerio de Salud y Protección Social de Colombia. 2015. Resolución 2690 de 2015. Diario Oficial No. 49.602 de 12 de agosto de 2015. [Internet]. Disponible en: http://extwprlegs1.fao.org/docs/pdf/col150819.pdf

35. Norma ISO 16649-2-2001. Microbiology of food and animal feeding stuffs horizontal method for the enumeration of â-glucuronidase positive E. coli. [Internet]. Disponible en: https://www.iso.org/ standard/29824.html
36. [NTC1325] Norma Técnica Colombiana. 2008. Quinta actualización de 200808-20. Productos cárnicos crudos procesados no enlatados. ICONTEC. Editada 2008-09-03. [Internet]. Disponible en: https://es.slideshare.net/jamesdays/ ntc1325-9772139

37. [OMS] Organización Mundial de la Salud. 2015. Estimaciones de la OMS sobre la carga mundial de enfermedades de transmisión alimentaria (ETA). Consultado: junio 19 de 2020. [Internet]. Disponible en: https://apps.who.int/iris/ bitstream/handle/10665/200047/ WHO_FOS_15.02_spa.pdf?sequence $=1$

38. [OMS] Organización mundial de la Salud. 2018. E. coli. [Internet]. Disponible en: https://www.who.int/es/newsroom/fact-sheets/detail/e-coli

39. Piedrahita D, Márquez T, Máttar $S$. 2001. Detección de Escherichia coli 0157: H7 en poblaciones porcinas, canal bovina y productos cárnicos en el departamento de Córdoba. Rev MVZ Córdoba 6: 119-126. doi: 10.21897/rmvz.532

40. Puig-Peña Y, Leyva Castillo V, Rodríguez Suarez A, Carrera Vara J, Molejón PL, Pérez Muñoz Y, Dueñas Moreira O. 2013. Calidad microbiológica de las hortalizas y factores asociados a la contaminación en áreas de cultivo en La Habana. Rev Habanera Cienc Méd 13: 111-119.

41. Raina R, Krishnappa V, Blaha T, Kann T, Hein W, Burke L, Bagga A. 2019. Atypical hemolytic uremic syndrome: an update on pathophysiology, diagnosis, and treatment. Ther Apher Dial 23: 4-21. doi: 10.1111/1744-9987.12763

42. Rangel JM, Sparling PH, Crowe C, Griffin PM, Swerdlow DL. 2005. Epidemiology of Escherichia coli O157:H7 Outbreaks, United States, 1982-2002. Emerg Infect Dis 11: 603609. doi: 10.3201/eid1104.040739

43. Reuben A, Treminio H, Arias ML, Chaves C. 2003. Presencia de Escherichia coli 0157:H7, Listeria monocy- 
togenes y Salmonella spp en alimentos de origen animal en Costa Rica. Arch Latinoam Nutr 53: 389-392.

44. Reyes-Rodríguez N, Talavera-Rojas M, Varela-Guerrero A, Barba-León J, Gutiérrez-Castillo A, Alonso-Fresán U. 2013. Prevalencia y resistencia a antibióticos de Escherichia coli O157:H7 aislada de canales de bovinos sacrificados en rastros del altiplano central mexicano. Rev Mex Cienc Pecu 4: 235-242.

45. Rodríguez-Cordero D, CarrascalCamacho AK. 2016. Manual de toma de muestras de Salmonella spp y Escherichia coli biotipo 1 en canales porcinas. Centro de Investigación y Transferencia de Tecnología del sector porcícola (CENIPORCINO). [Internet]. Disponible en: https://repository.agrosavia.co/bitstream/handle/ 20.500.12324/11529/80681_66864.pdf?sequence $=1 \&$ isAllowed $=\mathrm{y}$

46. Rubeglio EA, Tesone S. 2007. Escherichia coli $0157 \mathrm{H7}$ : presencia en alimentos no cárnicos. Arch Argent Pediatr 105: 193-194.

47. Rúgeles LC, Bai J, Martínez AJ, Vanegas MC, Gómez-Duarte G. 2010. Molecular characterization of diarrheagenic Escherichia coli strains from stools samples and food products in Co- lombia. Int J Food Microbiol 138: 282286. doi: $10.1016 /$ j.ijfoodmicro.2010.01.034

48. Stecher B, Hardt W. 2008. The role of microbiota in infectious disease. Trends Microbiol 16: 107-114. doi: 10.1016/ j.tim.2007.12.008

49. Stevens M, Ashbolt N, Cunliffe D. 2003. Review of coliforms as microbial indicators of drinking water quality recommendations to change the use of coliforms as microbial indicators of drinking water quality. Sidney, Australia. [Internet]. Available in: https:// www.scirp.org/(S (czeh2tfqw2 orz553k1w0r45))/reference/referencespapers.-aspx?referenceid $=2541530$.

50. Varela-Hernández JJ, Cabrera-Díaz E, Cardona-López MA, IbarraVelásquez LM, Rangel-Villalobos $H$, Castillo A, Torres-Vitela MR, et al. 2007. Isolation and characterization of Shiga toxin-producing Escherichia coli 0157 and non-0157 from beef carcasses at slaughter plant in México. Int J Food Microbiol 113: 237-241. doi: 10.1016/ j.ijfoodmicro.2006.06.028

51. Wilson JB, Clarke RC, Renwick $S A$, Rahn K, Johnson RP, Karmali MA, Lior H, et al. 1996. Vero cytotoxigenic Escherichia coli infection dairy farm families. J Infect Dis 74: 1021-1027. doi: 10.1093/infdis/174.5.1021 